\title{
A SPACE ADVENTURE CAMP AND PRE-UNIVERSITY OUTREACH
}

\author{
Witold Kinsner ${ }^{1}$, M.G.(Ron) Britton ${ }^{2}$, Jeff Cieszecki ${ }^{3}$, Wayne A. Ellis ${ }^{4}$, Alan Thoren ${ }^{5}$, Dario Schor ${ }^{1}$, \\ Brian Statham ${ }^{6}$, Greg Linton ${ }^{6}$, Tom Tessier $^{7}$, Rob Striemer ${ }^{8}$, Colleen Flather ${ }^{2}$, Barbara Bowen ${ }^{9}$, \\ and Norman Lee $e^{10}$ \\ ${ }^{1}$ Department of Electrical and Computer Engineering \\ ${ }^{2}$ Faculty of Engineering \\ University of Manitoba \\ Winnipeg, MB, Canada R3T 5V6 \\ ${ }^{3}$ Seven Oaks School Division, Winnipeg, MB \\ ${ }^{4}$ AppSpace Solutions Inc., Winnipeg, MB \\ ${ }^{5}$ The Winnipeg Amateur Radio Club, Winnipeg, MB \\ ${ }^{6}$ Canadian Forces School of Aerospace Studies, Winnipeg, MB \\ ${ }^{7}$ Solara Remote Data Delivery Inc., Winnipeg, MB \\ ${ }^{8}$ Shaftesbury High School, Winnipeg, MB \\ ${ }^{9}$ Manitoba Aerospace, Winnipeg, MB \\ and ${ }^{10}$ MindSet, Government of Manitoba, Winnipeg, MB \\ w.kinsner@ieee.org
}

\begin{abstract}
This paper presents a summary of the experience gained from several offerings of a space adventure camp for high-school students at a university campus. Pedagogical, organizational, logistical and safety issues are discussed. Linkages to other elements in our aerospace educational program are made, including a university mentorship for high-school students and the satellite design project. Support from over 20 organizations is reviewed, including the strong Manitoba aerospace industry, the amateur radio community, and several high schools.
\end{abstract}

Keywords: Outreach programs, teaching pre-university students, hands-on workshops, demonstrations.

\section{INTRODUCTION}

This paper describes experience from organizing and delivering a space adventure camp for high-school students offered at the University of Manitoba. This is one of several major pre-university outreach activities to attract talented students to engineering and sciences. Before discussing the space camp in detail, a summary of our philosophy and approaches to the pre-university outreach is provided, together with a broader context of outreach activities as recently introduced by the Institute of Electrical and Electronics Engineers (IEEE).

Attracting students to engineering is an increasingly challenging problem. One of the major reasons is the perception of students and their parents that there are no jobs in engineering because they have been outsourced to other countries. In response to this challenge, many universities have increased outreach activities to highschools, technical colleges, and even primary schools. The activities range from standard presentations about university capabilities, to hands-on workshops, special events, and dedicated interactions (mentorship) with selected students. However, although necessary, such traditional outreach presentations to students in primary schools, high schools, vocational schools, and technical colleges have produced limited results [Kins11].

A much more effective group of outreach activities focuses on teaching teachers (or training the trainers) through workshops and direct hands-on project development. This approach is considered most effective because of the multiplying factor (one teacher sees many students during a day or a week). Teaching teachers is described in [KiBC11], with several associated programs such as the Teachers In-Service Program (TISP) organized by the IEEE, as well as programs directed toward students such as TryEnginering [TryE11], TryScience [TryS11], TryNano [TryN11], eScientia [eSci11], and the planned TryComputing. That paper also discusses direct mentorship to senior high-school students. Although university mentorship to students addresses only a small number of students, it has a very high rate of success in terms of those students registering in engineering. The broader question of how we attract students to engineering and sciences is also addressed systematically in [KiBC11]. 


\section{THE SPACE CAMP CONCEPT}

While outer space was reserved for very few in the past, many more students today can find challenging opportunities in space-related education and jobs. In order to provide a place to explore such opportunities, an inexpensive one-week summer space adventure camp (SAC) has been developed at the University of Manitoba (UofM) for high-school students from Manitoba and elsewhere, as one element in our multi-facet space-related education program. The purpose of SAC is to encourage young men and women from high schools to engage in science, mathematics, engineering and technology. The SAC participants can experience science and engineering through hands-on workshops, demonstrations, tour to research facilities, short tutorials, and outdoors activities. The space camp presents the technical material in such a way that the students could realize quickly that engineering design of complex evolving cognitive systems for space (and other terrestrial applications) cannot be done by any trial-and-error approach, but through a systematic engineering design process (EDP) [Kins07], [Kins09]. Notice that "a complex system" means much more than "a complicated system." The space camp also teaches the students how to form teams, and how to work efficiently as teams, another requirement for designing complex systems.

Typical space-camp activities include: rocket building and launching (small and large); robot building and testing; high-altitude balloon launching; amateur radio (ham) operations; satellite ground station operation and its use for tracking of near-space payloads; fox hunting (transmitter locating); young engineers' satellite (YES2) and zero-G experiment; CubeSat design experience; Canadian Satellite Design Challenge (T-Sat) at the UofM; unmanned vehicles at UofM; simulation of orbital mechanics; Canadian Space Agency (CSA) workshops; demonstration of six high-technology labs at the Faculty of Engineering; space law; astronomy; industrial aerospace accomplishments (Magellan-Bristol); and small space business. The students have access to a multi-million dollar space-related software for simulation and exploration.

In order to prepare the students for the space camp, a Web-based course on space-related concepts is made available one month prior to SAC's commencement. The students are expected to pass it before the camp. Launching, tracking and recovering of a near-space balloon with a recoverable payload is done one day after the camp. Launching of a large rocket is done two days after the camp. Parents are also invited to participate in some of the activities.

The space camp is designed to achieve several longterm objectives, including: (a) to understand the engineering analysis-and-design process, and how ideas can be implemented —not just with lots of money, but in a smart way; (b) to learn how to work in teams; (c) to understand how the very-high level of science and engineering developed for space can be applied to our planet; (d) to understand the relationship between our planet and space; and (e) how to be good stewards of this planet.

There are other space camps such as the Space Camp in Cosmodome Building, Laval, Quebec [SpCa11], as well as the Space Camp and Academy in Huntsville, Alabama [SpAc11]. The former camp is for children age 9 to 15 , and lasts either 3 or 6 days. The facility was built at a cost of $\$ 30$ million, and has a replica of the Endeavour Shuttle and a NASA flight simulator. At least one of the authors has personal experience with this camp. The American Space Camp is designed for the youngest children grades 4 to 6 (ages 9 to 11), and has three tracks: space, aviation, and robotics. The Space Academy is for older children grades 7 to 9 (ages 12 to 14), and has three tracks: space, aviation, and robotics. The 6-day Advanced Space Academy is for children grades 10 to 12 (ages 15 to 18 ). It has two tracks: a mission specialist, a Shuttle pilot. More than 500 thousand students and adults attended the camp since its beginning in 1982 .

\section{SPACE CAMP ELEMENTS}

As summarized in the previous section, the space camp has many components that have to be delivered to 35 students, grade 9 to 11 , in a short time of 5 core days and three extension days. Each core day consists of 8 hours of instruction, not counting a short lunch. Each year, we have been learning how to deliver those components more effectively, and how to modify the components to achieve a deeper impact on the students.

\subsection{Space Camp Organization}

The space camp is organized by a group of volunteers consisting of university professors, highschool teachers, representative from the Manitoba Aerospace, representatives from the Canadian Forces School of Aerospace Studies, representative from the MindSet (The Manitoba Network for Science and Technology), and representatives from the amateur radio community. The daily management of the space camp has been provided by the Women in Science and Engineering (WISE) at the University of Manitoba. The WISE Kid-Netic Energy program provides Manitoba with up to 1000 workshops camps and clubs, reaching approximately 25,000 youth a year.

Preparation to the space camp takes nearly a year. Monthly meetings help in streamlining the activities such as budgeting, preparation of a space camp brochure, selection of topics covered each day, scheduling of the events so that they are mixed (seminars interspersed with 
hands-on activities and tours), booking of speakers, selection of space camp guides, preparation of identification badges, planning of take-home material (usually stored in a USB memory stick in the form of a bracelet that serves as an ID).

A post-camp review session is conducted shortly after the end of the camp. A written report is prepared with recommendations for improvements for the organizing committee.

\subsection{Enhancing Student Preparation}

In the past offerings of the space adventure camp (SAC), we found that the students were not prepared for it conceptually, and much time had to be spent to explain the space fundamentals. Consequently, a Web-based course on space-related concepts is being made available one month prior to SAC's commencement by the Canadian military. The course includes several essential topics to prime the students for the issues presented at the camp. The topics include: space environment, satellite design, orbital mechanics, satellite communications, satellite navigation, remote sensing from space, and spacelift. Quizzes are taken during the course. The students are expected to pass the course before the camp. Course instructors can monitor the student use of the course.

\subsection{Camp Orientation of Student and Parents}

In the past, students commenced the space camp with a full day of orientation and introductory material. We found that this produced a very serious information overload, as they had to learn not only about space, and many technical matters, but also about the facilities and camp logistics. Consequently, we introduced an orientation session in the afternoon before the commencement of the core camp (5 days) to describe the program itself, the logistics, safety procedures, and the facilities used during the camp. The president of the university welcomes the students and their guardians. The officials from the Manitoba Aerospace also welcome the camp participant on behalf of the Manitoba industry, thus connecting the camp to the jobs that would be available to the students after the university. We also distribute the camp schedule not only to the students, but also to their parents, guardians and friends. This assures that the parents are fully aware of the schedule and topics involved, and can assist the students in their study. It also removes the anxiety about the university and the location of the camp where the students can be dropped off safely.

\subsection{Space Camp Overview}

The first day of the core camp is dedicated to the camp's objectives, scope, safety (again), expected outcomes, and the intent to attract the students to the university. Overview of several Manitoba initiatives dedicated to enhancing student learning about aerospace are described, including the WinCube project (CubeSat overview, student high-altitude balloon launching at Seven Oaks and Shaftesbury high-schools (the Shatesbury High-Altitude Robotics Project, SHARP-2 [Stri11]), rocketry in Manitoba, and amateur radio for terrestrial and satellite communications. The introduction also includes a review of the pre-camp course and its value to the students.

\subsection{Hands-On Workshops}

The core of the space camp consists of hands-on workshops. The camp has three groups of workshops: (i) computational, (ii) engaging, and (iii) construction. The computational group includes: RoboMath, "Orbital Mechanics with STK", "Galaxy Zoo: Hubble". The engaging group has "Living and Working in the Unique Environment of Space" and "B-Cube Tracking Exercise," "SAE Car Simulator," and "Fox Hunting." The construction group includes: "Rocket Building and Launching" and "Robot Building."

\subsubsection{RoboMath Computational Workshop}

The Canadian Space Agency (CSA) has developed a Space Learning Program. For this program, a Manitoba company (Project Whitecard) developed a program called RoboMath [Robo11]. RoboMath and RoboMath3 are focused on curriculum specific math concepts at the grade 5/6 level and grade 9/10 level, respectively. Students learn in a 3D Space Station environment. Standing at the robotic workstation together with an avatar representing the Canadian astronaut, Julie Payette, students could solve mathematics problems based on the STS-127 mission and the robotic activities assigned to Julie Payette.

This workshop is presented and demonstrated by the president of Project Whitecard as one of the two CSA workshops. The company also demonstrates other spacerelated computational projects.

\subsubsection{Orbital Mechanics with STK}

The Satellite Tool Kit (STK) is a physics-based modelling and simulation software for space and over 20 other applications [STK11]. As developed by Analytical Graphics, Inc. (AGI), the software helps engineers and scientists in complex analysis of land, sea, air, and space assets in one integrated package. More specifically, it can be used to model a spacecraft behaviour both visually and analytically, and to estimate many important parameters for a mission. In this hands-on computational workshop, students model the trajectories of low-earth-orbiting satellites, GPS satellites operating in medium-earth-orbit, and geostationary satellites. The visualization 
demonstrates the differences between major orbits and some of the advantages and disadvantages of each. This multimillion-dollar software may be made available to the camp participants even beyond the camp itself.

\subsubsection{Living \& Working in Unique Environment of Space}

This CSA workshop engages students with various activities leading to problem solving in the unique space environment. Emphasis has been given to how different space is from the more familiar environments. Thought experiments and activities have been designed so that students could discover the differences easily by themselves. Examples have been given to reinforce the discovery process.

\subsubsection{B-Cube Tracking Exercise}

This workshop was developed to demonstrate to the students how a satellite ground station can be used to track the position of a payload. The workshop was originally designed for a physical high-altitude balloon (B-Cube) launch and tracking. However, since the BCube lunching depends on weather conditions, and usually has to be moved to different time slots or cancelled, the delivery of this valuable experience to the students was uncertain. Consequently, the high-orbit project was converted to tracking of the B-Cube payload located in a car traveling around the city (about $40 \mathrm{~km}$ in diameter). Since the modified tracking is independent of the weather, the workshop could be delivered as scheduled. An additional advantage of this terrestrial tracking is that each experiment produces a map of the electromagnetic radiation noise from the city, thus allowing us to map and predict the blind spots near horizon, a critical piece of knowledge in predicting communications with low-horizon satellites.

The students are divided into two groups, one operating the ground station and transmitting the GPS coordinates by voice, using ham radio frequencies, and the other group receiving the coordinates of the payload and placing its location on a city map (modified to display a grid matching the GPS coordinates received). Both groups switch their roles in the middle of the session. The activity is very engaging and educational to all the students.

\subsubsection{Fox Hunting \& Geocaching}

Finding a secret transmitter (bug) in one's house has been popularized in many action movies and novels familiar to students. Finding an illegal transmitter in an open space outside the house (i.e., fox hunting) is a much more complicated problem because of the size of the search area, as well as signal reflection from adjacent buildings and the electromagnetic radiation noise that may be masking the transmitter. Hams have developed many techniques to find such transmitters (e.g., $[\mathrm{MoCu} 87])$. Some of the techniques use directional antennas, receivers and triangulation to locate the bugs. Other techniques use sophisticated phase-difference and time-difference of arrival of the waves from the bug. Winnipeg radio community (and the first author of this paper) organized many fox hunts in the past, using fixedlocation and mobile foxes. That experience and fun will be transferred to the students at the camp this year.

Geocaching is another popular activity around the globe. It uses global positioning system (GPS) to locate hidden objects (treasures), and hop from one location to another, until the destination is found. Our space camp also provided these activities.

\subsubsection{Small \& Large Rocket Building and Launching}

There are three aspects to rocketry component of the space camp. First, students are guided through the construction and launch of a simple commercially produced rocket (e.g., Estes Wizard [EsWi11]). For most participating students, this is their first experience working with chemically-propelled rockets. Students learn firsthand how to construct the rockets, including safety procedures, and protocol for launching (using A8-3 motors [EsRE11]).

The second component is a presentation by the Manitoba Rocketry Group (MRG), highlighting aspects of high powered rocketry, including principles of rocketry design, examples of locally built rockets, and high powered rocketry licensing regulations.

The third aspect is student construction of a second commercially produced rocket (e.g., Estes Viking [EsVi11]) that allows various tail fin configurations ( 3 or 5 fins in various orientations) by the students. At the second launch, students are encouraged to review the impact of the various tail fin designs and the impact of using two engine sizes (A8-3 and B6-4 [EsRE11]).

\subsubsection{Tiny Robot Building}

The scope of this workshop is to assemble, test, and operate a tiny robot. It consists of three parts: (i) oral, (ii) hands-on development, and (iii) analysis. The oral presentation introduces the concept of a robot, and particularly the BEAM (Biology, Electronics, Aesthetics, and Mechanics) robot by discussing its components and their interactions and constraints. It then attempts to design a small robot that could be implemented with inexpensive components [Sola10]. The objective of this part is to show that mathematics, physics, electronics, circuits, and design principles are all needed to accomplish such a task. The hands-on part of the workshop demonstrates how a paper-design is translated into a practical implementation. The key intent of the entire workshop is to give the assembled and tested robot to each student so that they could experiment with their machines at school, and to show them to their parents and friends. This provides an important multiplying factor. The workshop is described in detail elsewhere [KiBC11]. 


\subsection{Presentations and Demos on Engineering Design}

\subsubsection{YES2 Satellite \& Zero-G Experiment}

The European Space Agency (ESA) developed a concept of space mail whereby a time-sensitive experiment or payload could be brought from an lowearth-orbiting (LEO) satellite back to the earth inexpensively and safely, without rocket fuel. This involves a tethered vehicle released sufficiently far (30 $\mathrm{km})$ from the LEO satellite so that the payload would start experiencing atmospheric drag and the tether could be cut. Finally, the kite-like descent of the payload could be intercepted in flight by an airplane. The concept was first tested on a Young Engineers' Satellite, YES1. The project continued on a successor, YES2, under the management of DeltaUtech in the The Netherlands. The first author of this paper assembled a group of undergraduate and graduate students from different universities (Team Canada) to design and build a flight computer for YES2 (e.g., [DGKK03], [KSPN09]). Together with a German and Spanish teams, we also developed a system to test tether dynamics in the zerogravity (zero-G) environment on a parabolic flight in Bordeaux, France. This extraordinary design and flight experience is shared with the space-camp students.

\subsubsection{CubeSat \& T-Sat Experience Overview}

The objective of these two presentations and demonstrations is to explain what a very small (a CubeSat, $10 \times 10 \times 10 \mathrm{~cm}, 1 \mathrm{~kg}$ ) picosatellite is, and how university students can design, build and test it. A UofM team of students has recently developed a CubeSat command and data handling $(\mathrm{CDH})$ unit, as a final-year capstone project [SSNK09]. The space-camp CubeSat presentation provides highlights of their $\mathrm{CDH}$ unit design experience. This includes an overview of the satellite components and some of the high-level functionality of the $\mathrm{CDH}$, followed by a live demonstration of the flight computer for the satellite connected to a solar panel from the robotics workshop described in [KiBC11]. This demonstration links the concepts from the robotics workshop (see Sec. 3.5.7) to the design of satellites, and engages many of the students in discussions about microprocessors for space, embedded applications, and ways of controlling the orientation of a satellite in space.

The T-Sat presentation goes one step further in that it describes the process of building a triple CubeSat (T-Sat) for a specific client. While the $\mathrm{CDH}$ constituted a single functional unit on the satellite, the T-sat has many parts, and must be designed to carry out experiments in space. The T-Sat team consists of about 80 university undergraduate and graduate students and 50 advisors from academia, aerospace, industry, military, radio, community, government and other groups. This is an unprecedented project in Canada, conducted under the umbrella of the first Canadian Satellite Design Challenge, as described in [KBSD11].

\subsubsection{Satellite Ground Station and Amateur Radio}

Amateur radio has been used by amateur radio operators (hams) for many years to communicate within a city and around the world, without or with wires. Deep friendship among hams is legendary. It is based on the common goal of acquiring knowledge to improve such low-power and long-distance communications, with the lowest possible disturbance to the environment, in order to make connections when all other communication means fail during disasters such as earthquakes and floods. Today, amateur radio also makes satellites and space accessible to hams and the public. The recentlycompleted UofM Satellite Ground Station [ScKT09] is demonstrated to the students by seasoned hams and new hams from the UofM Amateur Radio Society (UMARS). As an example, the camp students use SatPC32 to track a low-earth-orbiting amateur satellite to communicate with other amateur radio operators in North America.

\subsubsection{UofM Unmanned Vehicles \& Racing Cars}

Students from the UofM Departments of Mechanical/Manufacturing and Electrical/Computer Engineering designed, simulated and implemented many sophisticated flying and driving vehicles under the umbrella of the Society for Automotive Engineers (SAE). This presentation and video demonstration show the accomplishments of such students in various competitions, including cars and unmanned airplanes. The presentation is given by an experienced aerospace Engineer-In Residence who is also a mentor to the SAE teams.

\subsection{Presentations on Space-Related Issues}

\subsubsection{Astronomy}

A presentation on astronomy is intended to bridge the heavy technical aspects of the camp with physics, astrophysics, mathematics, and modelling of objects large and small. The talk is given by a very experienced local astronomer.

\subsubsection{Bristol in Space}

The accomplishments of our Manitoba aerospace industry are presented at the camp by an experienced designer from that industry. The presentation includes designing and building of large rockets, small satellites like the SciSat, and the entire design, simulation, construction, testing, and lunching process of space related objects. The demonstration includes many model vehicles and actual parts that have flown in near space. 


\subsubsection{Space Business}

In addition to very-large and large aerospace companies, there are also smaller companies that the students should be aware of. How would one start such a company? What does it take to run a small space-related company? In Manitoba, Solara Remote Data Delivery is one of such companies to provide client- and consumerfocused solutions and tools for secure, robust, reliable and timely wireless data communications. Their Field Tracker 2100 and the Solace line of communication and GPS tracking software suites are demonstrated. The talk also describes the operation of the Iridium satellite constellation and its relation to the Solara systems.

\subsubsection{Space Law}

What happens if our orbiting T-Sat collides with a Chinese satellite? Who owns space? Can we buy a lot on the Moon? Under a guidance of an expert, the spacecamp students discuss those and other questions during a presentation on the legal aspects of space.

\subsection{Tours to Research Labs}

University research laboratories often study the most difficult problems of our times. In order to demonstrate a broader spectrum of knowledge available at a university, short lab tours are organized at the UofM Faculty of Engineering during the space camp. The space-camp students are split into small groups, and rotate through the following labs.

\subsubsection{Industrial \& Medical Robotics Lab}

Since mechatronics (e.g., [Bolt03], [Brag02]) is prominent at the space camp in the form of rockets, robotics, and many other activities, a tour to the control and robotics lab is organized to demonstrate how robots can be designed, simulated and implemented for industrial and medical applications.

\subsubsection{Nanofabrication Lab}

Many of the space camp activities rely on high technology and its miniaturization in the form of not only electronics, but also mechanical devices. This tour takes the students to a clean room, and demonstrates how such mechatronic devices and system are developed. It also explains various applications of nanotechnology.

\subsubsection{Rapid Prototyping Lab}

Since designing of mechanical objects with the help of a computer is demonstrated in many space-camp activities, this tour shows how the designs can be prototyped quickly, without building mechanical mockups first. This rapid prototyping lab shows different techniques of three-dimensional (3D) printing of very complicated static and movable objects.

\subsubsection{Biomedical Engineering Lab}

Since signal acquisition, signal processing, and secure and reliable data transmission are discussed and demonstrated throughout the camp, this tour demonstrates how such systems can be developed and operated in the biomedical context that calls for extreme safety and intelligent interaction with people.

\subsection{Meet a Canadian Astronaut}

A Canadian space camp without a Canadian astronaut would not be complete. After all, Canada has played such an important part in many areas of space development, such as communications satellites (e.g., Anik A1 was the world's first national domestic satellite which gave the Canadian Broadcasting Corporation, CBC, the ability to reach the Canadian North for the first time), space robotics (e.g., the Shuttle Remote Manipulator System (SRMS), or Canadarm1 and 2 familiar to nearly all students today), and excellent astronauts (Marc Garneau, Roberta L. Bondar, Steven G. MacLean, Chris A. Hadfield, Robert (Bob) Thirsk, Bjarni V. Tryggvason, Dafydd (Dave) Williams, Julie Payette, and others). The two astronauts that conversed with our most recent space-camp students were Chris Hadfield and Bob Thirsk.

Well in advance of the camp, an astronaut is selected through CSA. On the first day of the space camp, our students are informed that they could converse with the selected Canadian astronaut. The astronaut's biography is discussed. The students are asked to prepare several important questions for the astronaut and discuss the questions with their guardians and friends. The following day, the questions are collected and discussed at a special session. The camp organizers review the questions, and a subset is submitted to the military for vetting. During the third day, the final selected subset of questions is announced to the students, and sent to the CSA for their approval. The final set is sent to NASA for their final approval. On the last day of the camp, the students have one hour to converse with the astronaut through a voice connection, while sitting at a round table with a microphone and many recording devices. A large picture of the astronaut is posted on a screen.

\subsection{Graduation Ceremony}

In the middle of the course, the concept of research project mentorship is discussed, and students are encouraged to apply. At the end of the graduation ceremony, the applications for mentorship are collected.

Following a feedback session (with a questionnaire and a discussion), a graduation ceremony is intended to close the core camp. A summary of the camp is provided first, followed by the distribution of small awards for 
students whose exceptional involvement was visible to most involved in the camp. This is followed by pizza for all. Parents, guardians and friends of the students also participate in the ceremony, together with all the instructors, mentors and representatives from the university and industry. It is also made clear that the camp has two additional activities open to all space-camp participants and their friends, as described next.

\subsection{Post-Camp Activities}

Two post-camp activities are available to students, their parents and friends: a high-altitude balloon launch one day after the end of the camp (Saturday), and a large rocket launch another day later (Sunday). Both events have been moved outside the regular schedule for several reasons. The most important is that the events depend on weather (rain, wind, thunderstorms), and when cancelled during the core camp days, require major changes to the schedule. Another reason is that since the events are dangerous, they cannot be done on the campus within the city, and transporting students to those remote locations takes time. The first event is done in the Birds Hill Park (at the Pope John Paul II Hill off Festival Drive near the East Gate), some $20 \mathrm{~km}$ north of the city and $40 \mathrm{~km}$ from the UofM. The second event is done in the La Barrière Park, 4403 Waverley Street, some $5 \mathrm{~km}$ south of the city and $10 \mathrm{~km}$ from the UofM. Both events are very spectacular, educational and impressive.

\section{CLOSING REMARKS}

Although a space camp requires much preparation and effort to deliver, its impact on students is substantial in terms of their exposure to science, mathematics and technology, as well as to engineering analysis, design, simulation, implementation, testing, installation and maintenance.

The camp has several key elements: (i) the hands-on workshops constitute the core of the camp, (ii) the demonstrations and discussions present projects that are too large to fit into the camp time table, and (iii) oral presentations and discussions address more general concepts that tie all the other elements together. To achieve diversity, each type of activities is interspersed with the alternative types.

The delivery of the camp events is done not only by experienced professors and teachers, but also by experienced university students whose enthusiasm and energy has always provided positive examples to the camp students.

The outcomes of the workshop were extraordinary in that most of the camp students completed and tested their projects successfully. Through the build-and-test procedures used in all the workshops, students were able to reduce the fear of embarking on such nontrivial projects. The experience gained by our undergraduate students who supervised the workshop participants was also significant.

We have succeeded in communicating the key message that the engineering development of useful and intelligent systems is a very exciting and creative process, but requires knowledge taught later in our undergraduate and graduate university courses.

\section{Acknowledgements}

This work was supported in part by the Faculty of Engineering, Department of Electrical and Computer Engineering, Department of Mechanical Engineering -all from the University of Manitoba, Canadian Forces School of Aerospace Studies, Canadian Space Agency, Canadian Space Society, Manitoba Rocketry Group (MRG), Magellan-Bristol Aerospace, Solara Remote Data Delivery Inc., AppSpace Solutions Inc., Royal Astronomical Society (RASC), Standard Aero, Analytical Graphics Inc., The Winnipeg Amateur Radio Club (WARC), WinCube, Aerospace Manitoba, The Manitoba Network for Science and Technology (MindSet), and the Natural Sciences and Engineering Research Council (NSERC) of Canada.

Special thanks go to all the instructors and engineering mentors in our successive space camps who brought their knowledge, excitements and encouragements to the students. We also thank all the university students who contributed their talent as teaching assistants in the space camps.

\section{References}

[Bolt03] W. Bolton, Mechatronics: Electronic Control Systems in Mechanical and Electrical Engineering. Harlow, UK: Prentice-Hall, 2003 (3rd ed.), 574 pp. ISBN: 0-131-21633-3.

[Brag02] Newton C. Braga. Robotics, Mechatronics, and Artificial Intelligences: Experimental Building Blocks for Designers. Burlington, MA: Newness, 2002, 297 pp. ISBN: 0-7506-7389-3 pbk.

[DGKK03] S. Dueck, N.Gadhok, M. Kinsner, J. Kraut, W. Kinsner, and T. Tessier, "YES2 DHS: A space tether control subsystem," in Proc. IEEE 2003 Can. Conf. Electrical \& Computer Eng., CCECE03 (Montré al, Que; May 4-7, 2003); ISBN: 0-7803-7782-6 (CDROM) Paper \#635; ISBN: 0-7803-7781-8 (printed), vol. 2 of 3, pp. 1287-1292, 2003.

[eSci11] e-Scientia, 2011. Available as of April 28, 2011 from

http://www.ieee.org/education_careers/education/preuni versity/e_scientia.html

[EsRE11] Estes Rocket Engines. 2011. Available as of April 28, 2011 from 
http://www.estesrockets.com/rockets/educator/001781a8-3-engine-bulk-pack

http://www.estesrockets.com/rockets/educator/001783b6-4-engine-bulk-pack

[EsVi11] Estes Rockets: Viking. 2011. Available as of April 28, 2011 from

http://www.estesrockets.com/rockets/kits/skill1/001949-vikingtm

[EsWi11] Estes Rockets:Wizard. 2011. Available as of April 28, 2011 from

http://www.estesrockets.com/001292-wizardtm

[Kins07] Witold Kinsner, "Towards cognitive machines: Multiscale measures and analysis" Intern. J. Cognitive Informatics and Natural Intelligence, vol. 1, no. 1, pp. 28-38, January-March 2007.

[Kins09] Witold Kinsner, "Challenges in the design of adaptive, intelligent and cognitive systems," Intern. J. Software Science \& Computational Intelligence, vol. 1, no. 3, pp. 16-35, July-Sept. 2009.

[Kins11] Witold Kinsner, "Creating excitement in learning and teaching," in Proc. IEEE Teachers-InService Program Workshop (Mississauga, ON; April 28-29, 2011) 2011.

[KiBC11] Witold Kinsner, M. G. (Ron) Britton, and Jeff Cieszecki, "Teaching-teachers: Could I design, build, and test a tiny smart robot?," in Proc. of Canadian Engineering Education Conference, CEEC11 (St. John's, NL: June 6-8, 2011), 2011.

[KBSD11] Witold Kinsner, M.D.(Ron) Britton, Dario Schor, Arash Fazel Darbandi, Kris Goodmanson, Cody Friesen, Emily Bashford, "Preliminary experience from the Canadian Satellite Design Challenge," in Proc. Can Engineering Education Conf. (St. John's, NL; June 6-8, 2011) 2011.

[KSPN09] W. Kinsner, D. Schor, J. Polak Scawcroft, C. Nichols, M. Kinsner, N. Gadhok, S. Dueck, and T. Tessier, "From YES2 to a picosatellite constellation: An example," in Proc. QB50 Workshop (Rhode-StGenèse, Belgium; 17 - 18 November 2009), Poster (http://www.vki.ac.be/QB50/download/workshop/poste rs/manitoba.pdf).

[MoCu87] Joseph D. Moell, KØOV, and Thomas N. Curlee, WB6UZZ, Transmitter Hunting: Radio Direction Finding Simplified. Blue Ridge Summit, PA: TAB Books, division of McGraw-Hill, 1987, 336 pp. \{ISBN number 0-8306-2701-4\}. Available as of May 2011 from http://www.homingin.com/

[Robo11] RoboMath. Saint-Hubert, QC: Canadian Space Agency, 2011. Available as of May 2011 from http://www.asc-csa.gc.ca/eng/missions/sts127/robomath.asp

[STK11] Satellite Tol Kit, STK. Analytical Graphics, Inc., 2011. Available as of May 2011 from http://www.agi.com/
[ScKT09] Dario Schor, Witold Kinsner, and Alan Thoren, "Satellite ground station emulator: an architecture and implementation proposal," in Proc. of the IEEE Canadian Conference on Electrical and Computer Engineering, CCECE09 (St. John's NL: May 3-6, 2009), pp. 874-879.

[SSNK09] Dario Schor, Jane Polak Scowcroft, Chris Nichols, and Witold Kinsner, "A command and data handling system for pico-satellite missions," in Proc. of the IEEE Canadian Conference on Electrical and Computer Engineering, CCECE09 (St. John's, NL: May 3-6, 2009), pp. 868-873.

[Sola10] SolarSpeeder SolaRoller 2. Calgary, AB: Solarbotics, 2010. Available as of June 2010 from http://www.solarbotics.com/products/k_ss/resources/

[SpAc11] Space Camp and Academy. Huntsville, AL, 2011. Available as of May 2011 from http://www.spacecamp.com/

[SpCa11] Space Camp Canada. Cosmodome, Laval, QC, 2011. Available as of May 2011 from http://www.cosmodome.org/

[Stri11] Robert Striemer, "The Shaftesbury high altitude robotics project," The Canadian Amateur, vol. 39, no. 1, pp. 50-51, January-February 2011.

[TryE11] TryEngineering, 2011. Available as of April 28, 2011 from http://www.tryengineering.org/

[TryN11] TryNano, 2011. Available as of April 28, 2011 from

http://www.ieee.org/education_careers/education/preuni versity/tispt/trynano.html

[TryS11] TryScience, 2011. Available as of April 28, 2011 from http://www.tryscience.org/
CEEC 2011

St. John's; June 6-8, 2011
ceec11_2c-SpCamp-v44.doc May 15, 2011 